\title{
PROPOSIÇÃO DE UM PROGRAMA DE CAPACITAÇÃO GERENCIAL EM UMA INSTITUIÇÃO FEDERAL DE ENSINO
}

\author{
PROPOSITION OF A MANAGEMENT TRAINING PROGRAM IN A FEDERAL EDUCATION \\ INSTITUTION
}

\section{Luiz Marcos Soares}

lm.soares@yahoo.com.br

Programa de Pós-Graduação em Administração/Universidade Federal Fluminense - Volta Redonda/RJ, Brasil https://orcid.org/0000-0002-7548-2441

\section{Resumo}

Pensar em desenvolvimento de competências organizacionais é pensar no desenvolvimento das competências gerenciais individuais. Esta pesquisa apresenta uma proposta de construção de um programa de capacitação gerencial em um Instituto Federal de Educação Profissional e Tecnológica. A abordagem é qualitativa com aplicação de questionário aos servidores e entrevistas semiestruturada aos gestores, utilizando-se da Análise de Conteúdo para categorizar e codificar as verbalizações dos entrevistados. Com a utilização dessa metodologia conseguiu-se, além de percepções, informações aprofundadas para construção de uma ação de capacitação gerencial estruturada em seis principais temáticas, que se estabeleceram como a espinha dorsal do programa de capacitação gerencial.

Palavras-chave: Competência. Capacitação. Gestores.

\begin{abstract}
Think about the development of organizational skills is think about the development of individual managerial skills. This research presents a proposal to build a managerial training program in a Federal Institute of Professional and Technological Education. The approach is qualitative with the application of a questionnaire to the servers and semi-structured interviews to the managers, using Content Analysis to categorize and code the verbalizations of the interviewees. With the use of this methodology got, in addition to perceptions, in-depth information was obtained for the construction of a managerial training action structured in six main themes, which were established as the backbone of the managerial training program.
\end{abstract}

Keywords: Competence. Training. Managers. 


\section{Introdução}

Nas Instituições Federais de Ensino (IFEs), os servidores podem, ao longo de suas carreiras na instituição, assumir coordenações, chefias de departamento, diretorias sistêmicas, Pró-Reitorias e, até chegar ao cargo de dirigente máximo, na Reitoria. No entanto, é fortemente presente o aspecto da rotatividade do exercício do cargo de gestão, dado seu caráter político e, em muitos casos, o ocupante do cargo não está preparado para o exercício da gestão.

$\mathrm{Na}$ gestão das IFEs, com muita frequência, profissionais competentes nas mais diversas áreas são propostos como reitores, diretores ou chefes, com o argumento de que demonstraram grande competência em cargos de gestão na Instituição.

No entanto, muitos dos atuais administradores da educação pública não foram formados para desempenhar papéis de gestores nas Instituições de Ensino em que trabalham.

Assim, as organizações públicas de ensino, segundo Campos (2007), têm sido alvo de críticas sobre os seus reais objetivos, rigidez de suas estruturas e ineficiência no uso de recursos escassos, sendo que, na maioria das vezes, os seus gestores são responsabilizados por tais problemas. É a ausência de competência gerencial influenciando diretamente no desempenho institucional.

Para ilustrar melhor a situação, pode-se citar como exemplo de medida para enfrentamento do problema, o de grandes empresas privadas que, ao se depararem com tal situação em seus ambientes organizacionais, encontraram na criação de Universidades Corporativas um caminho para promoverem a capacitação de seus funcionários em diversas temáticas (PIRES, 2008).

Inserindo o problema no contexto da organização pesquisada, observou-se que a deficiência em sua política de capacitação para os gestores está entre os problemas a serem enfrentados pela organização, evidenciando ser este um de seus pontos fracos dentro de uma análise ambiental com objetivos estratégicos realizada.

\section{Fundamentação Teórica}

\section{Competência gerencial}

Conforme definição de Ruas (2003), competência caracteriza-se como uma capacidade de se realizar algo, seja individual, em grupo ou organizacional, mediante mobilização de recursos e dado um contexto específico.

É preciso ressaltar que competência não é um estado ou um conhecimento que a pessoa tem, nem resultado de treinamento, na verdade esta é a mobilização dos conhecimentos e experiências para atender as demandas e exigências de determinados contextos, marcados em grande parte pelas relações de trabalho, cultura organizacional, imprevistos, limitações de tempo e também de recursos. (DUTRA et al., 2008)

E mais, ao afirmar que as organizações necessitam de profissionais com diferentes competências, Dutra (2004) levanta uma questão de grande relevância para o contexto dos Institutos Federais: que as competências individuais exigidas não são as mesmas para todas as pessoas, pois difere entre as que ocupam posição gerencial e as que ocupam uma posição técnica.

Assim, as competências gerenciais são destaque, já que, além de gerir as atividades organizacionais, os gestores devem desempenhar a função de líder da equipe, possuindo um perfil capaz de interagir de maneira interdisciplinar interligando a técnica com a maneira como os indivíduos executam e desenvolvem suas funções. (PAIVA; FERREIRA, 2013)

O gestor deve gerir os diversos tipos de situações através da assimilação de informações, visando à obtenção de vantagens competitivas; gerir a complexidade envolvida no dia a dia organizacional; gerir a adaptabilidade, inovando e buscando a melhoria constante de estratégias e processos; gerir equipes identificando e respeitando as 
diferenças; gerir incertezas, sabendo lidar com as modificações repentinas; e gerir o aprendizado, aprendendo e educando a equipe. (ALMEIDA; MOTTA, 2012)

Neste contexto, competência gerencial pode ser caracterizada como a capacidade de mobilizar, integrar e colocar em ação conhecimentos, habilidades e formas de atuar, a fim de atingir desempenhos configurados na missão organizacional e da área de atuação, ou seja, deve ser entendida como uma ação por meio das quais conhecimentos, habilidades e atitudes pessoais e profissionais são mobilizados. (RUAS et al., 2005)

No entanto, competências gerenciais não se dão única e exclusivamente por um processo natural. Desenvolver as próprias competências e as competências de outros é requisito fundamental para melhoria de desempenho da organização, onde o desenvolvimento de tais competências se dá por meio de programas direcionados à capacitação de profissionais (CRIPE e MANSFIELD, 2003).

\section{Capacitação de gestores}

A capacitação é uma ferramenta fundamental na gestão das organizações, não apenas pelo corpo operacional, mas também pelo staff gerencial, haja vista as contínuas transformações no ambiente interno e externo das organizações, transformando e intensificando a atividade gerencial. Cabe ao gestor analisar e solucionar os problemas da organização, convergindo o desempenho das pessoas com os objetivos estratégicos da organização. (PERIN, 2009)

Em estudo realizado, Longenecker e Fink (2005) evidenciaram diversos benefícios específicos associados à capacitação de gestores, afirmando que a eficácia do treinamento gerencial tem significativo impacto no desempenho dos gestores capacitados e, consequentemente, no desempenho da organização.

A concepção tradicional de treinamento estabelece uma educação profissional que busca adaptar o indivíduo ao trabalho dentro das organizações, preparando-o para o exercício de determinado cargo e cumprimento de determinada tarefa (BARRETO, 1995). Já numa concepção mais abrangente e atual de treinamento e desenvolvimento, o que se busca é aperfeiçoar as capacidades e motivações dos indivíduos, a fim de torná-los parte importante e valiosa dentro da organização. (MILKOVICH e BOUDREAU, 2000)

Com relação ao processo de treinamento, este deve possuir, necessariamente, quatro momentos: o diagnóstico das necessidades de treinamento, a programação ou construção do treinamento para atender às necessidades diagnosticadas, a implementação e execução da ação de capacitação e por fim, a avaliação dos resultados. (MARRAS, 2011)

Estudo realizado por Kanan e Zanelli (2011) com dirigentes de uma Instituição Federal de Ensino no país, corrobora a noção de importância em se capacitar os gestores organizacionais ao demonstrar que, apesar dos gestores pesquisados avaliarem positivamente suas competências no exercício da função gerencial, eles relataram que limitações ao desempenho efetivo da função de gestor também ocorriam. Essas limitações não estavam associadas apenas à falta de conhecimentos específicos nas questões administrativas, mas também às questões essencialmente gerenciais.

Como solução ao problema acima, as competências detectadas como necessárias a uma organização, mas que ainda não estão disponíveis precisam ser desenvolvidas através de práticas de treinamento. (SEIFFERT, 2005)

\section{Diagnóstico do problema}

Um gestor, seja em uma organização pública ou privada, deve localizar-se no espaço existente entre a unidade pela qual é responsável formalmente, o conjunto das outras diversas unidades existentes e o ambiente externo à organização. Tal proposição baseia-se no fato de que os gerentes dedicam grande parte de seu tempo, especialmente, às relações laterais com seus colegas e não somente com aqueles que lhe são subordinados. (MINTZBERG, 2010) 
E a transformação desses profissionais para o desempenho efetivo de suas funções gerenciais será possível através de sua devida capacitação profissional. A falta de formação gerencial específica tende a levar o dirigente, em muitas situações, a aprender a exercer sua função no próprio dia-a-dia organizacional, por tentativa e erro, resolvendo conflitos e atuando convenientemente nas mais diversas situações de tensão.

Nas Instituições Federais de Ensino (IFEs), os servidores podem, ao longo de suas carreiras na instituição, assumir coordenações, chefias de departamento, diretorias sistêmicas, Pró-Reitorias ou chegar ao cargo de dirigente máximo, na Reitoria, no entanto, é fortemente presente o aspecto da rotatividade do exercício do cargo de gestão, dado seu caráter político.

O contexto de ocupação de grande parte dos cargos de gestão nas IFEs obedece uma lógica política de indicação de nomes, onde o desempenho profissional dos servidores indicados, quando observado, caracteriza-se por uma análise pouco abrangente e baseada na área técnica específica do indicado. Essa, no entanto, não é uma realidade atual, como pode ser observado nas palavras de Rezende (1982), onde na gestão das IFEs, com muita frequência, engenheiros ou advogados competentes são propostos como reitores, diretores ou chefes, com o argumento de que demonstraram grande competência em suas áreas próprias de atuação.

Segundo Silva (2012), este é um dos grandes problemas enfrentados pela administração universitária: o fato de a maioria dos administradores universitários não ter formação para essa tarefa, sendo obrigada, dessa forma, a improvisar em seus papéis.

A partir do momento que a estrutura institucional é predefinida por parâmetros legais, e a característica do corpo de gestores é multidisciplinar, a proposta de solução do problema deve "atacar" a vertente menos rígida dentre as duas citadas, no caso o corpo de gestores multidisciplinar.

Entendido que a solução para o problema de pesquisa deva necessariamente passar pela capacitação dos gestores, uma nova pergunta se torna relevante: tal possibilidade de capacitação ainda não existe? A resposta para a pergunta é sim, existe!

Empresas privadas de ensino, escolas de governo e até mesmo programas do Ministério da Educação específicos para gestores existem ou já existiram num contexto em que a organização pesquisada pôde ou ainda pode participar, no entanto, contratar empresas privadas para capacitar seus gestores esbarra naquele que talvez seja $o$ principal entrave, o alto custo. Se considerarmos que essa organização possui mais de uma centena de cargos gerenciais, arcar com esse tipo de contratação para servidores que podem deixar suas funções gerenciais a qualquer momento, haja vista seu caráter de livre exoneração por parte do dirigente máximo é comprometer o orçamento institucional com uma ação que pode não ter efetividade.

Outro ponto desfavorável à contratação de empresas privadas reside no fato de que, conforme a legislação para contratações públicas em âmbito federal deve-se, sempre que possível, priorizar as escolas de governo para esse tipo de contração em relação às instituições privadas, no entanto, o governo federal, que conta atualmente com 13 instituições vinculadas ao poder executivo, possui apenas uma escola de governo atrelada ao Ministério da Educação, sem que possua em seu hall de oferta de cursos, um programa gerencial.

Instituições como a Escola Nacional de Administração Pública (ENAP), vinculada ao Ministério da Economia, apesar de possuir um programa de capacitação gerencial, não abrange todas as necessidades de capacitação da organização pesquisada, principalmente aquelas de ordem histórico-conceitual que somente um programa desenhado e estruturado conforme a demanda da instituição poderia oferecer.

Por fim, algumas ações específicas do Ministério da Educação foram implantadas na tentativa de minimizar esse problema junto a Rede Federal de Educação Profissional e Tecnológica, no entanto, com pouca amplitude, pois eram poucas vagas e direcionadas apenas ao alto escalão institucional.

Neste sentido, estruturar uma ação de capacitação que leve em consideração não apenas os principais pilares teóricos, mas também as especificidades organizacionais parece ser a melhor alternativa. 


\section{Procedimentos metodológicos}

A abordagem utilizada na pesquisa foi qualitativa, em virtude da utilização de questionário e entrevistas semiestruturadas no processo de coleta de dados.

Para a aplicação dos questionários e realização das entrevistas utilizou-se um erro de 10\%, para cima ou para baixo da proporção amostral obtida, e um nível de confiança de 90\%, que segundo Stevenson (2001), corresponde a uma probabilidade de o intervalo de confiança conter a verdadeira proporção populacional.

A partir dos documentos organizacionais disponíveis, especialmente o Relatório de Gestão publicado em 2018, tem-se tanto o número total de servidores, para aplicação dos questionários, quanto o número de gestores, para realização das entrevistas, onde, segundo Stevenson (2001):

$$
\mathrm{n}=\frac{\mathrm{Z}^{2} \cdot \hat{\mathrm{p}} \cdot(1-\hat{\mathrm{p}}) \cdot \mathrm{N}}{(\mathrm{N}-1) \cdot \mathrm{E}^{2}+\mathrm{Z}^{2} \cdot \hat{\mathrm{p}} \cdot(1-\hat{\mathrm{p}})}
$$

em que:

$\mathrm{N}$ : tamanho da população;

p̂: proporção amostral (que pode ser obtida à partir de uma amostra piloto);

E: erro de estimação (semi amplitude do intervalo de confiança);

Z: quantil da distribuição Normal (relacionado com o nível de confiança do intervalo de confiança);

Quando não se tem uma amostra piloto, então o valor $\hat{\mathrm{p}}$ será desconhecido. Neste caso, substitui-se $\hat{\mathrm{p}}$ por 0,5 (valor que fornece o intervalo de confiança mais amplo possível). Assim, a fórmula anterior reduz-se a:

$$
\mathrm{n}=\frac{0,25 \cdot \mathrm{Z}^{2} \cdot \mathrm{N}}{(\mathrm{N}-1) \cdot \mathrm{E}^{2}+0,25 \cdot \mathrm{Z}^{2}}
$$

Observa-se que $\hat{p} \cdot(1-\hat{p})=0,5 \cdot 0,5=0,25$ na fórmula acima.

Assim, conforme Relatório de Gestão, a organização pesquisada possui uma população de 1.212 servidores efetivos e ativos, gerando a amostra abaixo:

$\mathrm{E}=0,1 ;=1,65$ (quantil da dist. Normal para o IC de $90 \%$ ) e $\mathrm{N}=1212$.

Portanto:

$$
\mathrm{n}=\frac{0,25 \cdot 1,65^{2} \cdot 1212}{(1212-1) \cdot 0,1^{2}+0,25 \cdot 1,65^{2}} \approx 64 \text { questionários respondidos }
$$

Ou seja, para aplicação dos questionários, dado o universo de 1212 servidores da organização e considerando um erro de estimação de 10\%, bem como um nível de confiança de $90 \%$, estes devem ser aplicados a um mínimo de 64 servidores para garantir a representatividade da amostra. 
Já no universo gerencial, ela possui, segundo o Relatório de Gestão, 329 (trezentos e vinte e nove) cargos gerenciais, numa estrutura que se divide em 75 (setenta e cinco) Cargos de Direção-CD e 254 (duzentas e cinquenta e quatro) Funções Gratificadas-FG, no entanto:

72 funcões são destinadas às Coordenações de Curso (FCC) e que 46 funcões comissionadas são FG03, FG-04 e FG05, cujo valor remuneratório se mostra inadequado, além de não estarem contempladas no modelo de dimensionamento proposto pela Portaria MEC n 246, de 15 de abril de 2016.

A citação acima pôde ser melhor entendida a partir de duas entrevistas. Em uma delas o gestor entrevistado enumerou que apenas as FG-01 e FG-02 possuem caráter gerencial, não apenas no aspecto dos valores pecuniários a elas atreladas, mas também pela complexidade maior das atribuições e do número de servidores envolvidos sob essas Funções, e que as Funções de Coordenação de Curso, apesar de existirem, não são atualmente contempladas pela legislação dos Institutos Federais que trata da alocação dos cargos gerencias nos IFs, ou seja:

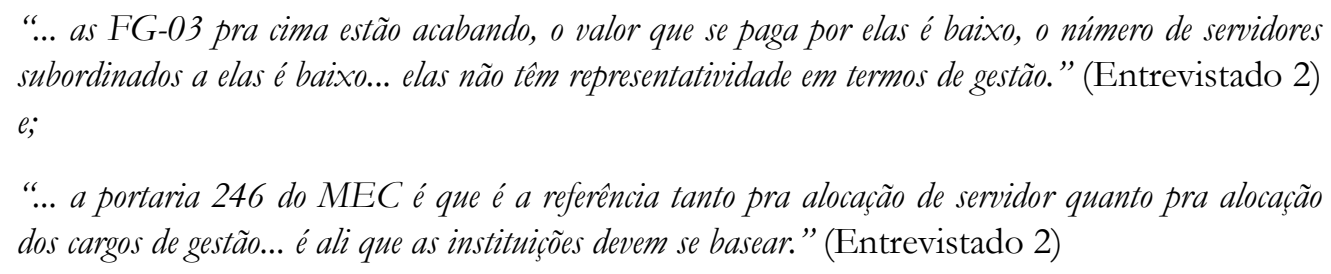

Em outra entrevista, um dos gestores explicou que os coordenadores de cursos não possuem caráter gerencial na estrutura da organização:

"... nós temos as Diretorias de Ensino e as Chefias de Departamento que fazem a ponte com os professores, na nossa estrutura não são os coordenadores de cursos que gerenciam os docentes e sua atuação, é o Diretor de Ensino ou Chefe de Departamento... é na Diretoria e na Chefia de Departamento que se tem equipe e recursos pra serem geridos." (Entrevistado 9)

Dessa maneira, esta pesquisa delimitou como cargos gerenciais na estrutura da organização, os Cargos de Direção e as Funções Gratificadas dos níveis 01 e 02. De forma complementar a informação acima, a Diretoria de Gestão de Pessoas da organização informou a existência discriminada de 56 FG-01 e 80 FG-02.

Sendo assim, para efeitos de composição da amostra abaixo considerou-se o universo de 211 cargos gerenciais aptos a comporem o universo de entrevistas da pesquisa.

Portanto:

$$
\mathrm{n}=\frac{0,25 \cdot 1,65^{2} \cdot 211}{(211-1) \cdot 0,1^{2}+0,25 \cdot 1,65^{2}} \approx 51 \text { gestores entrevistados }
$$

A partir da utilização desses procedimentos de coleta buscou-se obter respostas e maior compreensão das questões organizacionais, através dos questionários, assim como maior aprofundamento sobre as competências consideradas essenciais à prática gerencial na organização, mediante utilização das entrevistas semiestruturadas.

Entretanto, a partir da décima quinta entrevista com os gestores ficou claro para o pesquisador que algumas respostas se repetiam a cada nova entrevista, apresentando saturação na coleta de dados, já que nenhum novo elemento era encontrado. (NASCIMENTO, et al., 2018)

Dessa forma, foram realizadas mais cinco entrevistas na tentativa de obtenção de novos dados e informações que pudessem contribuir para a construção do artefato proposto na pesquisa, porém, sem êxito. Assim, a nova amostra das entrevistas com os gestores se restabeleceu em vinte entrevistas.

Também foi utilizada a observação direta participante que, conforme Gil (2008), consiste na "participação real do conhecimento na vida da comunidade, do grupo ou de uma situação determinada". 
Após a coleta das informações, seus dados foram analisados a partir da utilização de ferramentas estatísticas descritivas, para a aplicação de questionário, e análise de conteúdo, para se categorizar as respostas das entrevistas.

\section{Apresentação e análise dos resultados}

A solução proposta, capacitar os servidores investidos em cargos de gestão, foi obtida a partir da aplicação de um questionário e realização de entrevistas.

O questionário versou sobre o perfil dos gestores sob a ótica dos servidores subordinados, onde os respondentes, Técnicos-Administrativos em Educação e Professores da organização pesquisada, que exercem ou exerceram função gerencial, avaliaram 48 pontos conforme tabela 1.

Tabela 1 - Resumo do perfil do gestor sob a ótica dos servidores subordinados

\begin{tabular}{|c|c|c|c|c|c|}
\hline $\begin{array}{l}\text { PERFIL DO GESTOR SOB A ÓTICA } \\
\text { DOS SERVIDORES } \\
\text { SUBORDINADOS }\end{array}$ & $\begin{array}{l}\text { Discordo } \\
\text { totalmente }\end{array}$ & $\begin{array}{l}\text { Discordo } \\
\text { em parte }\end{array}$ & $\begin{array}{l}\text { Não tenho } \\
\text { opinião }\end{array}$ & $\begin{array}{l}\text { Concordo } \\
\text { em parte }\end{array}$ & $\begin{array}{l}\text { Concordo } \\
\text { totalmente }\end{array}$ \\
\hline \multicolumn{6}{|c|}{ Confiança e credibilidade } \\
\hline $\begin{array}{l}\text { Confio nas informações prestadas sob } \\
\text { responsabilidade da minha chefia }\end{array}$ & $1,6 \%$ & $6,3 \%$ & $1,6 \%$ & $52,4 \%$ & $38,1 \%$ \\
\hline $\begin{array}{l}\text { Confio nos serviços prestados sob } \\
\text { responsabilidade da minha chefia }\end{array}$ & $1,6 \%$ & $6,3 \%$ & $3,2 \%$ & $57,1 \%$ & $31,7 \%$ \\
\hline \multicolumn{6}{|c|}{ Compartilhamento } \\
\hline $\begin{array}{l}\text { Minha chefia compartilha as informações } \\
\text { de modo que a execução das atividades } \\
\text { não fique condicionada apenas à sua } \\
\text { presença }\end{array}$ & $1,6 \%$ & $14,3 \%$ & $11,1 \%$ & $47,6 \%$ & $25,4 \%$ \\
\hline $\begin{array}{l}\text { As atividades só podem ser executadas se } \\
\text { meu chefe estiver presente }\end{array}$ & $54,0 \%$ & $30,2 \%$ & $4,8 \%$ & $9,5 \%$ & $1,6 \%$ \\
\hline $\begin{array}{l}\text { Minha chefia incentiva } \\
\text { compartilhamento de ideias da equipe }\end{array}$ & $7,9 \%$ & $14,3 \%$ & $9,5 \%$ & $34,9 \%$ & $33,3 \%$ \\
\hline $\begin{array}{l}\text { Minha chefia incentiva o } \\
\text { compartilhamento de atividades na equipe }\end{array}$ & $7,9 \%$ & $17,5 \%$ & $7,9 \%$ & $34,9 \%$ & $31,7 \%$ \\
\hline $\begin{array}{l}\text { Minha chefia incentiva } \\
\text { compartilhamento de soluções propostas } \\
\text { pela equipe }\end{array}$ & $6,3 \%$ & $14,3 \%$ & $6,3 \%$ & $47,6 \%$ & $25,4 \%$ \\
\hline $\begin{array}{l}\text { Minha chefia não tem o hábito de } \\
\text { incentivar a participação da equipe de } \\
\text { trabalho }\end{array}$ & $33,3 \%$ & $20,6 \%$ & $14,3 \%$ & $23,8 \%$ & $7,9 \%$ \\
\hline \multicolumn{6}{|c|}{ Disponibilidade } \\
\hline $\begin{array}{l}\text { Minha chefia se mantém disponível para } \\
\text { discutir as solicitações por mim } \\
\text { apresentadas }\end{array}$ & $0,0 \%$ & $7,9 \%$ & $0,0 \%$ & $39,7 \%$ & $52,4 \%$ \\
\hline $\begin{array}{l}\text { Minha chefia se mantém disponível para } \\
\text { discutir as dúvidas por mim apresentadas }\end{array}$ & $0,0 \%$ & $6,3 \%$ & $1,6 \%$ & $33,3 \%$ & $58,7 \%$ \\
\hline $\begin{array}{l}\text { Minha chefia se mantém disponível para } \\
\text { discutir as sugestões por mim apresentadas }\end{array}$ & $0,0 \%$ & $7,9 \%$ & $1,6 \%$ & $36,5 \%$ & $54,0 \%$ \\
\hline \multicolumn{6}{|c|}{ Comprometimento } \\
\hline $\begin{array}{l}\text { Minha chefia busca atingir os objetivos } \\
\text { organizacionais }\end{array}$ & $1,6 \%$ & $14,3 \%$ & $4,8 \%$ & $36,5 \%$ & $42,9 \%$ \\
\hline
\end{tabular}




\begin{tabular}{|c|c|c|c|c|c|}
\hline $\begin{array}{l}\text { Minha chefia não se preocupa com os } \\
\text { objetivos organizacionais }\end{array}$ & $54,0 \%$ & $20,6 \%$ & $4,8 \%$ & $14,3 \%$ & $6,3 \%$ \\
\hline \multicolumn{6}{|c|}{ Flexibilidade } \\
\hline $\begin{array}{l}\text { Minha chefia compreende novas situações } \\
\text { de trabalho, aceita novas ideias e as } \\
\text { transforma em ações }\end{array}$ & $4,8 \%$ & $11,1 \%$ & $9,5 \%$ & $49,2 \%$ & $25,4 \%$ \\
\hline $\begin{array}{l}\text { Minha chefia procura compreender novas } \\
\text { situações de trabalho, aceita novas ideias, } \\
\text { mas tem dificuldade de transformá-las em } \\
\text { ações }\end{array}$ & $12,7 \%$ & $15,9 \%$ & $7,9 \%$ & $47,6 \%$ & $15,9 \%$ \\
\hline \multicolumn{6}{|c|}{ Aplicação do conhecimento } \\
\hline $\begin{array}{ll}\text { Minha chefia aplica seu conhecimento e } \\
\text { experiência para melhorar o } \\
\text { desenvolvimento das atividades }\end{array}$ & $6,3 \%$ & $4,8 \%$ & $11,1 \%$ & $39,7 \%$ & $38,1 \%$ \\
\hline $\begin{array}{l}\text { Minha chefia não aplica seu conhecimento } \\
\text { e experiência para melhorar o } \\
\text { desenvolvimento das atividades }\end{array}$ & $44,4 \%$ & $34,9 \%$ & $12,7 \%$ & $4,8 \%$ & $3,2 \%$ \\
\hline \multicolumn{6}{|c|}{ Relacionamento interpessoal } \\
\hline $\begin{array}{l}\text { Minha chefia se relaciona de forma cordial } \\
\text { com as pessoas dos diversos níveis } \\
\text { hierárquicos e culturais }\end{array}$ & $3,2 \%$ & $4,8 \%$ & $0,0 \%$ & $22,2 \%$ & $69,8 \%$ \\
\hline $\begin{array}{l}\text { Minha chefia busca manter o ambiente de } \\
\text { trabalho agradável }\end{array}$ & $1,6 \%$ & $11,1 \%$ & $1,6 \%$ & $20,6 \%$ & $65,1 \%$ \\
\hline $\begin{array}{l}\text { Minha chefia busca manter o ambiente de } \\
\text { trabalho produtivo }\end{array}$ & $1,6 \%$ & $9,5 \%$ & $6,3 \%$ & $30,2 \%$ & $52,4 \%$ \\
\hline $\begin{array}{l}\text { Minha chefia não dá atenção ao ambiente } \\
\text { de trabalho }\end{array}$ & $57,1 \%$ & $20,6 \%$ & $9,5 \%$ & $7,9 \%$ & $4,8 \%$ \\
\hline \multicolumn{6}{|c|}{ Comunicação } \\
\hline $\begin{array}{l}\text { Minha chefia possui capacidade de se } \\
\text { expressar de maneira clara e objetiva }\end{array}$ & $4,8 \%$ & $11,1 \%$ & $1,6 \%$ & $47,6 \%$ & $34,9 \%$ \\
\hline $\begin{array}{l}\text { Minha chefia possui capacidade de saber } \\
\text { ouvir os outros }\end{array}$ & $3,2 \%$ & $7,9 \%$ & $1,6 \%$ & $31,7 \%$ & $55,6 \%$ \\
\hline $\begin{array}{l}\text { Minha chefia possui capacidade de dar } \\
\text { respostas consistentes }\end{array}$ & $4,8 \%$ & $17,5 \%$ & $7,9 \%$ & $46,0 \%$ & $23,8 \%$ \\
\hline $\begin{array}{l}\text { Minha chefia possui capacidade de } \\
\text { convencimento }\end{array}$ & $4,8 \%$ & $19,0 \%$ & $11,1 \%$ & $49,2 \%$ & $15,9 \%$ \\
\hline $\begin{array}{l}\text { Minha chefia possui dificuldade de } \\
\text { comunicação }\end{array}$ & $31,7 \%$ & $20,6 \%$ & $9,5 \%$ & $25,4 \%$ & $12,7 \%$ \\
\hline \multicolumn{6}{|c|}{ Planejamento } \\
\hline $\begin{array}{l}\text { Minha chefia é capaz de visualizar e } \\
\text { organizar as sequências de ações } \\
\text { necessárias para atingir os objetivos e } \\
\text { metas do setor }\end{array}$ & $4,8 \%$ & $25,4 \%$ & $7,9 \%$ & $41,3 \%$ & $20,6 \%$ \\
\hline $\begin{array}{l}\text { Minha chefia apresenta dificuldade em } \\
\text { visualizar e organizar as sequências de } \\
\text { ações necessárias para atingir os objetivos } \\
\text { e metas do setor }\end{array}$ & $22,2 \%$ & $22,2 \%$ & $7,9 \%$ & $36,5 \%$ & $11,1 \%$ \\
\hline \multicolumn{6}{|c|}{ Capacidade de resolução de problemas e conflitos } \\
\hline $\begin{array}{l}\text { Minha chefia possui capacidade } \\
\text { resolver problemas no dia-a-dia do } \\
\text { trabalho de forma eficaz }\end{array}$ & $6,3 \%$ & $15,9 \%$ & $4,8 \%$ & $50,8 \%$ & $22,2 \%$ \\
\hline $\begin{array}{l}\text { Minha chefia possui capacidade de } \\
\text { resolver conflitos pessoais no dia-a-dia do } \\
\text { trabalho de forma eficaz }\end{array}$ & $4,8 \%$ & $25,4 \%$ & $9,5 \%$ & $36,5 \%$ & $23,8 \%$ \\
\hline $\begin{array}{l}\text { Minha chefia possui dificuldade em } \\
\text { resolver problemas e conflitos pessoais no } \\
\text { dia-a-dia do trabalho de forma eficaz }\end{array}$ & $22,2 \%$ & $27,0 \%$ & $7,9 \%$ & $30,2 \%$ & $12,7 \%$ \\
\hline
\end{tabular}




\begin{tabular}{|c|c|c|c|c|c|}
\hline \multicolumn{6}{|c|}{ Comportamento ético } \\
\hline $\begin{array}{l}\text { Minha chefia respeita as pessoas no } \\
\text { trabalho }\end{array}$ & $1,6 \%$ & $3,2 \%$ & $1,6 \%$ & $20,6 \%$ & $73,0 \%$ \\
\hline $\begin{array}{l}\text { Minha chefia é justa com as pessoas no } \\
\text { trabalho }\end{array}$ & $4,8 \%$ & $9,5 \%$ & $9,5 \%$ & $25,4 \%$ & $50,8 \%$ \\
\hline $\begin{array}{l}\text { Minha chefia é impessoal em suas ações } \\
\text { no trabalho }\end{array}$ & $6,3 \%$ & $17,5 \%$ & $14,3 \%$ & $31,7 \%$ & $30,2 \%$ \\
\hline Minha chefia trata com zelo o bem público & $0,0 \%$ & $0,0 \%$ & $6,3 \%$ & $19,0 \%$ & $74,6 \%$ \\
\hline \multicolumn{6}{|c|}{ Criatividade e Inovação } \\
\hline $\begin{array}{l}\text { Minha chefia possui capacidade criativa ou } \\
\text { inovadora no trabalho }\end{array}$ & $14,3 \%$ & $9,5 \%$ & $17,5 \%$ & $41,3 \%$ & $17,5 \%$ \\
\hline $\begin{array}{l}\text { Minha chefia possui capacidade criativa ou } \\
\text { inovadora no trabalho que gerem a } \\
\text { otimização nos processos e formas de } \\
\text { trabalho }\end{array}$ & $11,1 \%$ & $17,5 \%$ & $14,3 \%$ & $38,1 \%$ & $19,0 \%$ \\
\hline $\begin{array}{l}\text { Minha chefia não possui capacidade } \\
\text { criativa ou inovadora }\end{array}$ & $30,2 \%$ & $25,4 \%$ & $19,0 \%$ & $17,5 \%$ & $7,9 \%$ \\
\hline \multicolumn{6}{|c|}{ Capacitação e desenvolvimento profissional } \\
\hline $\begin{array}{l}\text { Minha chefia busca se qualificar e } \\
\text { aprimorar-se profissionalmente na sua área } \\
\text { de atuação }\end{array}$ & $7,9 \%$ & $4,8 \%$ & $15,9 \%$ & $33,3 \%$ & $38,1 \%$ \\
\hline $\begin{array}{l}\text { Minha chefia não busca se qualificar e } \\
\text { aprimorar-se profissionalmente na sua área } \\
\text { de atuação }\end{array}$ & $46,0 \%$ & $23,8 \%$ & $12,7 \%$ & $9,5 \%$ & $7,9 \%$ \\
\hline \multicolumn{6}{|c|}{ Capacitação e desenvolvimento profissional da equipe } \\
\hline $\begin{array}{l}\text { Minha chefia percebe as necessidades de } \\
\text { capacitação da equipe de trabalho }\end{array}$ & $6,3 \%$ & $15,9 \%$ & $4,8 \%$ & $49,2 \%$ & $23,8 \%$ \\
\hline $\begin{array}{l}\text { Minha chefia propõe a capacitação e } \\
\text { desenvolvimento da equipe de trabalho }\end{array}$ & $12,7 \%$ & $15,9 \%$ & $7,9 \%$ & $30,2 \%$ & $33,3 \%$ \\
\hline $\begin{array}{llll}\text { Minha chefia não dá atenção às } & \text { à } \\
\text { necessidades } & \text { de } & \text { capacitação } & \text { e } \\
\text { desenvolvimento da equipe de trabalho } & \\
\end{array}$ & $41,3 \%$ & $33,3 \%$ & $3,2 \%$ & $14,3 \%$ & $7,9 \%$ \\
\hline \multicolumn{6}{|c|}{ Adaptabilidade } \\
\hline $\begin{array}{l}\text { Minha chefia possui capacidade de } \\
\text { adaptar-se às mudanças nas rotinas } \\
\text { organizacionais }\end{array}$ & $0,0 \%$ & $14,3 \%$ & $17,5 \%$ & $42,9 \%$ & $25,4 \%$ \\
\hline $\begin{array}{l}\text { Minha chefia é resistente a mudanças nas } \\
\text { rotinas organizacionais }\end{array}$ & $33,3 \%$ & $27,0 \%$ & $19,0 \%$ & $15,9 \%$ & $4,8 \%$ \\
\hline \multicolumn{6}{|c|}{ Desempenho geral } \\
\hline $\begin{array}{l}\text { Analisando as afirmativas anteriores, avalio } \\
\text { que um desempenho organizacional } \\
\text { satisfatório passa, necessariamente, pela } \\
\text { devida capacitação gerencial dos seus } \\
\text { gestores }\end{array}$ & $3,2 \%$ & $0,0 \%$ & $3,2 \%$ & $12,7 \%$ & $81,0 \%$ \\
\hline $\begin{array}{l}\text { Analisando os itens anteriores avalio que a } \\
\text { organização onde atuo profissionalmente } \\
\text { possui um quadro de gestores } \\
\text { devidamente capacitados para a prática da } \\
\text { gestão }\end{array}$ & $27,0 \%$ & $36,5 \%$ & $4,8 \%$ & $25,4 \%$ & $6,3 \%$ \\
\hline $\begin{array}{l}\text { Analisando os itens anteriores avalio que a } \\
\text { organização onde atuo profissionalmente } \\
\text { promove o desenvolvimento de } \\
\text { competências gerenciais aos servidores } \\
\text { nomeados para cargos de gestão }\end{array}$ & $38,1 \%$ & $28,6 \%$ & $6,3 \%$ & $20,6 \%$ & $6,3 \%$ \\
\hline
\end{tabular}

Fonte: Dados da pesquisa 
E cabe, nesse momento, um destaque ao desempenho geral dos gestores, avaliados a partir de três prismas. O primeiro, que um desempenho organizacional satisfatório passa, necessariamente, pela devida capacitação gerencial dos seus gestores. Aqui, 92,7\% dos servidores concordam com essa afirmativa, sendo que $81 \%$ concordam totalmente, evidenciando uma necessidade organizacional premente.

Num segundo prisma, 63,5\% dos servidores discordaram que a organização onde atuam profissionalmente possui um quadro de gestores devidamente capacitados para a prática da gestão. Discordam ainda, 66,7\% dos servidores, que a organização promova o desenvolvimento de competências gerenciais aos servidores nomeados para cargos de gestão.

Em suma, as afirmativas dos servidores denotam certa deficiência organizacional quanto à capacidade de se colocar em prática ações mais objetivas, que envolvam a efetiva busca por resolução de conflitos entre servidores, e não apenas a escuta dos problemas; ou que envolvam uma comunicação organizacional mais estratégica, voltada para os objetivos planejados estrategicamente, e não apenas para uma comunicação por pura formalidade.

Já para a obtenção de informações mais detalhadas acerca da função gerencial dentro da organização, foi utilizada a técnica de entrevistas semiestruturadas com os gestores, mediante aplicação do roteiro de perguntas abaixo.

\begin{tabular}{|l|l|}
\hline $\mathbf{N}^{\mathbf{o}}$ & \multicolumn{1}{|c|}{ PERGUNTAS } \\
\hline $1^{\mathrm{a}}$ & Qual seu nome e cargo? \\
\hline $2^{\mathrm{a}}$ & Possui quantos anos de experiência profissional e há quanto tempo você atua como gestor? \\
\hline $3^{\text {a }}$ & Qual a sua formação e quais cursos já fez na área gerencial? \\
\hline $4^{\mathrm{a}}$ & Como chegou à função de gestor? \\
\hline $5^{\text {a }}$ & $\begin{array}{l}\text { Quais são para você as principais responsabilidades do gestor numa autarquia federal de ensino como a que } \\
\text { atua? }\end{array}$ \\
\hline $6^{\mathrm{a}}$ & Quais os aspectos positivos do trabalho como gestor? \\
\hline $7^{\mathrm{a}}$ & E quais os aspectos negativos dessa função? \\
\hline $8^{\text {a }}$ & Quais os temas técnicos mais críticos em sua área de atuação. Conte sobre as dificuldades enfrentadas. \\
\hline $9^{\text {a }}$ & $\begin{array}{l}\text { Quais os temas comportamentais/cognitivos mais críticos em sua área de atuação. Conte sobre as } \\
\text { dificuldades enfrentadas. }\end{array}$ \\
\hline $10^{\text {a }}$ & O que você pensa sobre o desenvolvimento de competências dos servidores. \\
\hline $11^{\text {a }}$ & E o desenvolvimento de competências gerenciais? \\
\hline $12^{\text {a }}$ & $\begin{array}{l}\text { Considerando as características da organização em que atua, quais temáticas não podem faltar num processo } \\
\text { de capacitação gerencial interno? }\end{array}$ \\
\hline $13^{\text {a }}$ & O que você recomendaria aos futuros gestores? \\
\hline $14^{\text {a }}$ & $\begin{array}{l}\text { Gostaria de acrescentar alguma coisa à sua entrevista que possa colaborar com a minha pesquisa? Algo que } \\
\text { tenha esquecido ou considera importante? }\end{array}$ \\
\hline
\end{tabular}

A análise dessas informações se deu com base na técnica de análise de conteúdo, que segundo Bardin (2011), caracteriza-se como um conjunto de técnicas de análise das comunicações, utilizando-se de procedimentos sistemáticos e objetivos na descrição do conteúdo das mensagens. Tal análise provê suporte adequado aos pesquisadores que pretendem desenvolver estudos no campo da Administração a partir de uma abordagem analítica crítica e reflexiva, com o objetivo de complementar a utilização de outras técnicas, como o questionário (MOZZATO; GRZYBOVSKI, 2011).

Para atender ao propósito da pesquisa, de construção de um artefato que possa gerar competências gerenciais básicas aos gestores em uma instituição federal de ensino, estabeleceu-se três categorias de análise representativas da expressão do sujeito da pesquisa, isto é, baseadas na fala dos entrevistados e codificadas posteriormente em blocos de textos (verbalizações) que se associavam, por afinidade conceitual, a temas definidos com base em tais verbalizações, conforme Quadro 1. 
Quadro 1 - Quadro matricial das categorias de análise

\section{CATEGORIA 1: RESPONSABILIDADES DE UM GESTOR}

Pontos de convergência a partir do questionamento de quais seriam as principais responsabilidades de um gestor na organização pesquisada, levando-se em consideração suas características organizacionais.

\begin{tabular}{|c|c|}
\hline Temas & Verbalizações associadas \\
\hline \multirow{9}{*}{ Pessoas } & $\begin{array}{l}\text { E1: Mais do que o conhecimento técnico, ele tem que saber gerir pessoas (...) tentar } \\
\text { motivar. }\end{array}$ \\
\hline & E5: O grande desafio é o gestor saber lidar com pessoas. \\
\hline & E6: A gestão de pessoas. \\
\hline & E7: Incentivar o servidor. \\
\hline & E8: Por lidar com pessoas, a gestão delas é das principais responsabilidades. \\
\hline & E10: A gestão das equipes é fundamental. \\
\hline & E13: Fazer a gestão das equipes, liderar. \\
\hline & $\begin{array}{l}\text { E14: Trabalhar o sentido comportamental é a base pra desempenhos satisfatórios de } \\
\text { uma equipe. }\end{array}$ \\
\hline & E19: Fazer uma boa gestão das pessoas, que seja motivadora. \\
\hline \multirow{3}{*}{ Função Pública } & $\begin{array}{l}\text { E4: Trabalhar suas ações para o crescimento da instituição, dada a responsabilidade } \\
\text { social que temos. }\end{array}$ \\
\hline & $\begin{array}{l}\text { E9: Mais importante é saber que estamos lidando com a coisa pública, fazendo para a } \\
\text { sociedade. }\end{array}$ \\
\hline & $\begin{array}{l}\text { E17: Devolver algo pra sociedade, essa é nossa função. É isso que ela espera de um } \\
\text { gestor público. }\end{array}$ \\
\hline \multirow{7}{*}{ Planejamento Estratégico } & E2: Conhecimento do todo da instituição (...) saber um pouco sobre todas as áreas. \\
\hline & $\begin{array}{l}\text { E3: Ficar apagando os incêndios do dia-a-dia atrapalha muito o papel do } \\
\text { gerenciamento (...) tem que ter alinhamento com a necessidade estratégicas da } \\
\text { instituição }\end{array}$ \\
\hline & E10: Realizar o planejamento, principalmente. \\
\hline & E11: Se não planejar e otimizar, a instituição vai ficar para trás. \\
\hline & E12: Planejamento é básico, atuar de acordo com as diretrizes da instituição. \\
\hline & E16: Atingir os objetivos estratégicos traçados. \\
\hline & E20: Fazer com que a equipe entregue os resultados pactuados. \\
\hline
\end{tabular}

CATEGORIA 2: TEMAS BASILARES INERENTES À ROTINA GERENCIAL

Pontos de convergência a partir do questionamento de quais temas não poderiam deixar de compor um Programa de Formação Gerencial na organização pesquisada, levando-se em consideração suas características organizacionais.

Temas

E1: Desenvolver lideranças eu consigo pensar agora.

E2: Liderança é importantíssima.

E3: Acho que a questão da gestão das pessoas, dos conflitos também é relevante, mas num menor nível se comparado à gestão de projetos e a questão do planejamento, por exemplo.

E4: Na parte comportamental, as grandes corporações, num ambiente altamente competitivo, eles têm preocupação muito grande com formação de lideranças, porque nós não teríamos?

E8: Por fim, tem que saber organizar as relações humanas, às vezes você muda um funcionário de setor e ele piora ou vice-versa, o gestor de ter essa capacidade.

E11: Essa parte de relação entre as pessoas é muito importante. Resolução de conflitos. A gente precisa saber lidar com os outros melhor porque reflete lá na frente.

E14: Aspectos cognitivos, normalmente não se dá atenção a isso, mas pra gestores são tópicos básico, como resolução de conflitos, formação de lideranças, e por aí vai.

E15: O gestor precisa ter boa noção de como motivar sua equipe.

E17: Penso que resolução de conflitos.

E18: Liderança (...) nessa linha.

E19: Acho que motivação, nessa parte de pessoal.

E20: Acredito que motivação de servidores. 


\begin{tabular}{|c|c|}
\hline \multirow{4}{*}{ Finanças Públicas } & $\begin{array}{l}\text { E3: Outra coisa é a parte financeira, porque a gestão fica a cargo da Pró-Reitoria de } \\
\text { Administração e os projetos acabam sendo prejudicados. }\end{array}$ \\
\hline & E6: Visão geral e ampla sobre orçamento e finanças. \\
\hline & E8: A parte financeira e orçamentária é importante. \\
\hline & E11: Essa parte de orçamento é básico. \\
\hline \multirow{7}{*}{ Compras Públicas } & E4: As aquisições, compras é básico. \\
\hline & E6: Visão geral e ampla de licitações. \\
\hline & E8: A licitação é fundamental, porque tudo tem de ser licitado. \\
\hline & E10: Licitação sem dúvida. \\
\hline & E11: Essa parte de comprar é básico. \\
\hline & E12: Noção de contratações é básico também. \\
\hline & $\begin{array}{l}\text { E13: Toda a temática da parte de licitação precisa ser conhecida não apenas pelo } \\
\text { pessoal da área. }\end{array}$ \\
\hline \multirow{5}{*}{ Comunicação } & $\begin{array}{l}\text { E4: Acho que a capacidade de comunicação do gestor é fundamental, aliás, bem } \\
\text { importante. }\end{array}$ \\
\hline & E9: A comunicação é essencial pro gestor. \\
\hline & E16: Comunicação é essencial. Sem ela, quando se é gestor, tudo fica mais difícil. \\
\hline & E17: Como o gestor pode trabalhar melhor a comunicação. \\
\hline & $\begin{array}{l}\text { E20: Acrescentaria a capacidade de comunicação. Um gestor que sabe se expressar, } \\
\text { consegue motivar melhor os servidores a atingirem aquilo que se propõe. }\end{array}$ \\
\hline \multirow{8}{*}{ Planejamento Estratégico } & E1: Gestão estratégica. \\
\hline & $\begin{array}{l}\text { E2: A gente tem gestores que são professores as vezes de história, engenharia, que } \\
\text { não têm a mínima noção de planejamento e gestão administrativa e são eles que vão } \\
\text { depois ocupar vários cargos. }\end{array}$ \\
\hline & $\begin{array}{l}\text { E3: Bom, acho que gestão por projetos e planejamento estratégico e gerenciamento de } \\
\text { projetos é o principal. }\end{array}$ \\
\hline & $\begin{array}{l}\text { E5: As questões de planejamento estratégico têm de estar como um livro de bolso de } \\
\text { todo gestor, do mais alto ao mais baixo escalão, porque ele é fundamental pra se } \\
\text { atingir a missão. }\end{array}$ \\
\hline & E10: Acho que ter conhecimento sobre o planejamento é fundamental. \\
\hline & E12: Acho que atuação com foco em objetivos claros e definidos pela gestão. \\
\hline & E18: Foco nos objetivos institucionais e coisas mais nessa área. \\
\hline & E20: Acredito que planejamento estratégico. \\
\hline \multirow{5}{*}{$\begin{array}{l}\text { Conhecimento } \\
\text { Organizacional }\end{array}$} & E5: O primeiro ponto é conhecer a nossa instituição. \\
\hline & $\begin{array}{l}\text { E6: Pra se evitar a tentativa e erro, de pronto, conhecimento de Administração } \\
\text { Pública e do IF. }\end{array}$ \\
\hline & E8: Conhecer a instituição também é básico, o organograma pelo menos. \\
\hline & E11: Tem que conhecer o Instituto, a história, a realidade atual. \\
\hline & $\begin{array}{l}\text { E19: Acho que é importante ter ao menos uma noção da instituição. Se tem muito } \\
\text { gestor que não conhece a instituição, imagina a maioria dos demais servidores. }\end{array}$ \\
\hline \multicolumn{2}{|c|}{ CATEGORIA 3: TEMAS CRÍTICOS INERENTES À ROTINA GERENCIAL } \\
\hline \multicolumn{2}{|c|}{$\begin{array}{l}\text { Pontos de convergência a partir do questionamento de quais são os temas técnicos e comportamentais } \\
\text { mais críticos/sensíveis na rotina dos gestores. }\end{array}$} \\
\hline Temas & Verbalizações associadas \\
\hline \multirow{4}{*}{ Pessoas } & $\begin{array}{l}\text { E1: Eu penso que o gestor tem muita responsabilidade no clima organizacional, o } \\
\text { clima afeta todo o trabalho. }\end{array}$ \\
\hline & $\begin{array}{l}\text { E2: Interpretação da legislação de pessoal porque cada um tem a sua, esse é o maior } \\
\text { desafio. }\end{array}$ \\
\hline & $\begin{array}{l}\text { E3: O servidor entra na administração pública com algumas expectativas e elas não se } \\
\text { concretizam. É difícil motivar e essas questões atrapalham com certeza a } \\
\text { produtividade. }\end{array}$ \\
\hline & $\begin{array}{l}\text { E4: O gerenciamento de pessoas é diferente no setor público, pois tem-se uma } \\
\text { questão legal, ou seja, a gente precisa conhecer as atribuições dos cargos. O gestor tem } \\
\text { que ter parceiros, e não mandar pra alguém obedecer, isso não funciona em lugar } \\
\text { nenhum, ainda mais no serviço público, cabe a ele desenvolver uma boa rede de } \\
\text { relacionamento. }\end{array}$ \\
\hline
\end{tabular}




\begin{tabular}{|c|c|}
\hline & E5: Necessitamos de uma gestão de pessoas mais inovadora. \\
\hline & E6: Acho que conflitos e lideranças são as mais relevantes. \\
\hline & E7: Acho que motivar o servidor é o mais difícil. \\
\hline & E9: Sensibilizar os servidores é o mais difícil. \\
\hline & E14: Conflitos entre servidores. \\
\hline & E15: A motivação dos servidores. \\
\hline & E14: Resolver os conflitos entre servidores. \\
\hline & E16: Acho que liderança é uma questão relevante. \\
\hline & E18: Não somos líderes, então é difícil conseguir certas transformações \\
\hline & E19: Não sei, acho que lidar com a desmotivação é muito difícil. \\
\hline & $\begin{array}{l}\text { E20: Motivar, porque nós temos, na pior das hipóteses, um retorno financeiro, mas a } \\
\text { equipe normalmente não. }\end{array}$ \\
\hline & E1: Diretores de todas as áreas precisam saber sobre orçamento. \\
\hline Finanças Públicas & E6: Ter noções de orçamento perpassa por todas as demais áreas da instituição. \\
\hline & E11: Todo mundo tinha que saber um pouco de orçamento. \\
\hline Comunicação & E9: A capacidade de interlocução entre as diversas áreas é muito importante. \\
\hline & $\begin{array}{l}\text { E4: A parte de aquisições de equipamentos e insumos, que envolve a contratação em } \\
\text { si. }\end{array}$ \\
\hline Compras Públicas & E6: Bem, a área de licitações perpassa por todas as demais áreas da instituição. \\
\hline & E8: Licitação é um caos, são tantas variáveis. \\
\hline & E11: Todo mundo tinha que saber um pouco de licitação. \\
\hline & E3: O sistema integrado de gestão utilizado pela instituição é o maior desafio. \\
\hline & $\begin{array}{l}\text { E4: Tem que haver planejamento estratégico atrelado as aquisições da instituição, por } \\
\text { exemplo. Saber qual o direcionamento da instituição pras diversas áreas. }\end{array}$ \\
\hline & $\begin{array}{l}\text { E5: A gente precisa pensar em investir na qualidade e melhoria dos servidores, mas } \\
\text { pra uma finalidade e missão institucional. }\end{array}$ \\
\hline & E9: Sensibilizar os servidores para atingir algo maior é o mais difícil. \\
\hline Planejamento & E10: Definir as prioridades, as estratégias do Instituto, também é bem complicado. \\
\hline & $\begin{array}{l}\text { E12: Trabalhar de uma maneira que todos busquem os objetivos comuns à Instituição } \\
\text { é um grande ponto crítico. }\end{array}$ \\
\hline & E18: Falta de foco nos objetivos estratégicos. \\
\hline & $\begin{array}{l}\text { E19: Foca-se muito no dia-a-dia e olha-se pouco pro futuro. Faz-se muito, mas } \\
\text { planeja-se pouco. }\end{array}$ \\
\hline & $\begin{array}{l}\text { E20: Difícil fazer todos pensarem e atuarem de uma maneira mais uniforme. Cada um } \\
\text { acaba trabalhando conforme suas convicções, não há um objetivo claro e comum. }\end{array}$ \\
\hline Conhecimento & $\begin{array}{l}\text { E4: Qualquer instrumento de ingresso ou manutenção, por exemplo, é bem } \\
\text { complexo. Edital, chamada é um desafio técnico. Constroem esses instrumentos sem } \\
\text { conhecer as implicações. A gente tem pouca informação jurídica pra construir esses } \\
\text { documentos. }\end{array}$ \\
\hline Organizacional & E5: Muitos que atuam aqui não conhecem a dinâmica de funcionamento do Instituto. \\
\hline & E9: A gente tem grande dificuldade de ajustar e unificar procedimentos. \\
\hline & E10: Acho que os procedimentos internos pouco definidos. \\
\hline & E13: A padronização das ações para toda a instituição \\
\hline
\end{tabular}

Fonte: Dados da pesquisa

Os dados obtidos com as entrevistas associadas à categoria de análise 1 - responsabilidades de um gestor foram agrupados em três temas: pessoas, função pública e planejamento estratégico. Dentre as 20 entrevistas realizadas, em nove delas, os entrevistados apontaram assuntos pertinentes à gestão das pessoas como responsabilidades intrínsecas à função gerencial.

Esse entendimento de quase metade dos entrevistados ganha respaldo nas palavras de Libâneo (2003), que enfatiza que um gestor escolar deve coordenar, mobilizar, motivar, liderar e delegar responsabilidade aos 
membros da equipe, além de acompanhar o desenvolvimento das ações, prestar contas e por fim submeter à apreciação da equipe o desenvolvimento das decisões tomadas coletivamente.

Essa percepção pode ser observada no trecho da entrevista abaixo:

“(...) o grande desafio é o gestor saber lidar com pessoas e formarmos lideranças, porque a administração pública tem suas peculiaridades, pois você pode ter conhecimento técnico e experiência, mas se você não entender que precisa gerir pessoas (...) isso é o grande desafio da administração pública" ENTREVISTADO 5

A segunda temática mais apontada pelos entrevistados relacionou-se com aspectos de planejamento e estratégias organizacionais. De fato, o tema possui grande relevância à medida que todas as atividades dentro de uma organização precisam estar alinhadas com a busca do objetivo organizacional comum. Para tanto, um planejamento estratégico estruturado depende da capacidade de planejar e percebe-se que o hábito de planejar está intimamente ligado ao perfil de cada gestor. (OLIVEIRA, 2010)

As principais responsabilidades de um gestor, para sete dos 20 entrevistados, relacionam-se à capacidade de planejar estrategicamente suas ações:

“(...) ficar apagando os incêndios do dia-a-dia atrapalha muito o papel do gerenciamento, tem que ter alinhamento com as necessidades estratégicas da instituição e não aquela coisa de realizar projetos que caiam de para quedas pra atender um ou outro." ENTREVISTADO 3

Interessante ressaltar um dos entrevistados que conseguiu conjugar, em uma verbalização, os dois temas acima tratados, a responsabilidade dos gestores com as pessoas e também com o planejamento:

"Importante fazer com que a equipe entregue os resultados pactuados (...) fazer uma boa gestão das pessoas, motivadora, mas pra atingirem os objetivos da instituição.” ENTREVISTADO 19

Por fim, o tema "função pública", aqui entendida como a função social do órgão público e sua interação com a sociedade, aparece como o terceiro mais evidenciado pelos entrevistados:

"A primeira coisa é que estamos lidando com a coisa pública, fazendo para a sociedade, ter responsabilidade e fazer uma análise crítica, pensar no retorno pra sociedade é muito importante." ENTREVISTADO 9

A segunda categoria de análise trata dos aspectos basilares, fundamentais e imprescindíveis ao universo do gestor na organização pesquisada, sob a ótica dos entrevistados e a partir da pergunta de quais temas não poderiam deixar de compor um Programa de Formação Gerencial no âmbito organizacional, levando-se em consideração suas características organizacionais.

Considerando que os entrevistados estavam aptos a apontar aspectos técnicos e comportamentais, optou-se por codificar as verbalizações em seis temas - pessoas, finanças públicas, compras públicas, comunicação, planejamento estratégico e administração/gestão - a partir da afinidade temática do que foi dito nas entrevistas.

O tema "pessoas" foi eleito por doze, dos 20 entrevistados, como um ponto crucial e necessário na capacitação dos gestores. Nesse universo, aspectos de liderança, gestão de conflitos, relacionamento interpessoal e motivação foram os abordados:

"Na parte comportamental, as grandes corporações, num ambiente altamente competitivo, eles têm preocupação muito grande com formação de lideranças e sucessores, porque nós não teríamos?" ENTREVISTADO 4

“(...) essa parte de relação entre as pessoas é muito importante, (pausa) resolução de conflitos. Até teve uma palestra aqui ano passado, foi muito bom, mas foi uma palestra rápida. Isso tem que ter num curso pra capacitar o gestor, a gente precisa saber lidar com os outros melhor, com esses conflitos, porque reflete lá na frente". ENTREVISTADO 11 
Percebe-se a partir das entrevistas que, assim como a capacidade de liderança, o gerenciamento dos conflitos internos existentes deve ser abordado num contexto de capacitação. Conforme Elias et al. (2013), o papel do gestor público na mediação e gestão do conflito tem grande relevância, uma vez que cabe a ele identificar e conduzir as situações de conflito dentro da organização.

O segundo tema mais lembrado pelos entrevistados como sendo essencial para que os gestores se capacitem é o relacionado ao planejamento estratégico.

De fato, o tema é de extrema relevância dentro das organizações, e em se tratando de organizações públicas de ensino, além de relevante, é também relativamente novo. Há duas razões que diferenciam o planejamento estratégico de uma organização privada e uma pública de ensino. A primeira delas está relacionada à natureza de prestadora de serviços dos órgãos públicos. A segunda razão diz respeito ao amadorismo gerencial evidenciado em organizações públicas acadêmicas (PASCUCI, et al., 2016):

“(...) a gente tem gestores que são professores as vezes de história, engenharia, que não têm a minima noção de planejamento e gestão administrativa e são eles que vão depois ocupar vários cargos." ENTREVISTADO 2

"As questões de planejamento estratégico têm de estar como um livro de bolso de todo gestor, do mais alto ao mais baixo escalão, porque ele é fundamental pra gente atingir a missão institucional." ENTREVISTADO 5

A importância de o gestor conhecer, ainda que forma básica, aspectos de compras públicas e finanças públicas foram mencionados, respectivamente, por sete e quatro entrevistados, que afirmaram serem esses temas basilares no universo de conhecimento dos gestores na organização pesquisada, como pode ser verificado em alguns trechos das entrevistas, abaixo:

"(...) o gestor de todas as áreas tem que ter uma visão geral e ampla de licitações, orçamento e finanças, que possa dar um norte pra ele.” ENTREVISTADO 6

Os outros dois temas apontados por metade dos 20 entrevistados, como essenciais num contexto de capacitação gerencial são a capacidade de comunicação que o gestor deve possuir e o conhecimento da organização pesquisada.

Abaixo, segue uma verbalização dos entrevistados que converge para o entendimento da importância da capacidade de comunicação dos gestores:

“(...) acrescentaria a capacidade de comunicação. Um gestor que sabe se expressar consegue motivar melhor os servidores a atingirem aquilo que se propõem.”ENTREVISTADO 20

Finalizando os temas que seriam basilares para o desenvolvimento de competências gerenciais, tem-se a necessidade de conhecimento da instituição de ensino pesquisada enquanto organização pública:

“(...) o primeiro ponto (que uma capacitação gerencial deve conter) é conhecer a nossa instituição, sua carga bistórica, o impacto dela na sociedade, qual o papel dessa instituição em termos regionais, a formação cidadã desses nossos alunos, qual a participação desses alunos pro setor produtivo, ou seja, entender qual é a missão da instituição, e os gestores tem de ter isso muito bem aderido a sua rotina de atuação, pra que o gestor não caminhe prum lado contrário ao da instituição." ENTREVISTADO 5

“(...) tem que ser voltado (a capacitação gerencial) pra nossa realidade também, não adianta muito esses cursos prontos porque eles não conhecem a gente e a gente não dispões de recurso pra capacitar todo mundo. Tem que conhecer o Instituto, a bistória, a realidade atual." ENTREVISTADO 11

Corroborando as percepções acima, Pereira (2013), afirma que o conhecimento da organização pode ser considerado como a base do seu know-how e do seu modus operandi, gerando, assim, as bases de suas práticas. 
Em complemento à categoria de análise 2, onde os entrevistados puderam expressar-se sobre os assuntos que, segundo os mesmos, não poderiam ficar de fora de um contexto de capacitação gerencial, a categoria de análise 3 teve por objetivo identificar os pontos, técnicos e comportamentais, considerados críticos em suas rotinas gerenciais.

Novamente, as verbalizações convergiram para os aspectos já identificados em outros momentos da entrevista, e cada nova entrevista, os temas associados às pessoas, ao planejamento, às finanças, às compras governamentais, à capacidade de comunicação e ao conhecimento organizacional eram reafirmados, evidenciando a saturação teórica nesta pesquisa qualitativa.

De toda forma, importante e relevante atentar para o fato de que quinze dos 20 entrevistados, isto é, $75 \%$ dos gestores respondentes afirmaram que os aspectos relacionados à gestão das pessoas eram os mais críticos.

Novamente, a temática relacionada ao planejamento estratégico aparece como segundo ponto mais evidenciado, onde nove dos 20 entrevistados apontaram ser esse um dos temas mais críticos no dia-a-dia organizacional. Organizacionalmente, a falta de uma cultura voltada aos aspectos de cumprimento de metas e resultados, ou mesmo de eficiência administrativa, tem sido cada vez mais latente no âmbito da organização pesquisada e perceptível pelos gestores:

"Planejamento é um problema. Tem que baver planejamento estratégico atrelado as aquisições da instituição, por exemplo. Saber qual o direcionamento da instituição pras diversas áreas. Você tem que saber se as suas ações estão atreladas aos objetivos macro da instituição." ENTREVISTADO 4

"Tem que trabalhar de uma maneira que todos busquem os objetivos comuns à Instituição, isso é um problema e isso é planejamento." ENTREVISTADO 12

"Foca-se muito no dia-a-dia e olha-se pouco pro futuro. Faz-se muito, mas planeja-se pouco." ENTREVISTADO 19

Os temas associados às finanças públicas e compras públicas, mais uma vez foram apontados, agora como sendo críticos na organização pesquisada, do ponto de vista da atuação do gestor:

"Diretores de todas as áreas precisam saber sobre orçamento, isso é crítico." ENTREVISTADO 1

"Acho que a parte de orçamento é o mais crítico, porque perpassa por todas as demais áreas da instituição." ENTREVISTADO 6

"Bem (...) a área de licitacõoes perpassa por todas as demais áreas da instituição, então eu penso ser, mais do que crítica, ser também muito relevante." ENTREVISTADO 6

“Licitação é um caos, são tantas variáveis, não dá pra ficar no escuro.” ENTREVISTADO 8

Por fim, os aspectos relacionados à organização em si, seu funcionamento e o devido conhecimento da sua estrutura por parte dos gestores, é uma preocupação novamente apontada pelos entrevistados:

"Muitos que atuam aqui não conbecem a dinâmica de funcionamento do Instituto." ENTREVISTADO 5

De forma esquemática, a partir dos apontamentos dos respondentes do questionário e das entrevistas, os temas preferíveis ou considerados relevantes para composição de um programa de capacitação gerencial na organização pesquisada podem ser mais bem visualizados no Quadro 2, a seguir. 
Quadro 2 - Quadro Resumo

\begin{tabular}{|c|c|}
\hline \multicolumn{2}{|c|}{ ÁREAS DE RELEVÂNCIA EM UM PROGRAMA DE CAPACITAÇÃO GERENCIAL NA } \\
ORGANIZAÇÃO PESQUISADA
\end{tabular}

Fonte: Dados da pesquisa

A partir da realização das entrevistas com gestores da organização, semiestruturadas, como já dito, através de um roteiro com perguntas que objetivavam extrair informações mais detalhadas e complementares acerca dos conhecimentos básicos necessários ao desempenho da função gerencial, vários tópicos foram citados, convergindo-se para seis principais temas, conforme tabela acima.

Dessa maneira, o objetivo de extração das temáticas consideradas relevantes foi atingido, levando-se em consideração a experiência e percepção daqueles que desempenham ou já desempenharam alguma atividade de gestão na organização pesquisada, identificando com clareza os assuntos e abordagens que mais encontravam dificuldade de conduzir, seja por desconhecimento técnico ou mesmo resistência pessoal.

Ou seja, trata-se de uma identificação clara e direta, por parte dos gestores, dos gargalos e pontos críticos de atuação em suas rotinas enquanto dirigentes das mais variadas frentes organizacionais em um órgão público de ensino federal, evidenciando, assim, os subsídios necessários para construção da proposta de um programa de capacitação gerencial em sua estrutura.

\section{Proposta de intervenção}

A partir do seu produto final, propõe-se oportunizar um instrumento interno de promoção da competência gerencial através de um Programa de Capacitação Gerencial para a organização pesquisada, impactando toda a estrutura organizacional, seus gestores e demais servidores e por consequência, a sociedade beneficiária dos serviços prestados por um corpo de gestores melhor capacitados.

Os níveis gerenciais encontrados em sua estrutura e adotados nesta pesquisa são os cargos de direção (CD) e as funções gratificadas (FG) até o segundo nível, conforme explicitado nos procedimentos metodológicos.

Quadro 3 - Composição dos cargos gerenciais na organização pesquisada

\begin{tabular}{|c|c|}
\hline CÓDIGO & OCUPANTE \\
\hline CD-01 & Reitor e Diretores de Campus \\
\hline CD-02 & Pró-Reitores \\
\hline CD-03 & Diretores Sistêmicos \\
\hline CD-04 & Diretores e Coordenadores-Gerais \\
\hline FG-01 & Coordenadores ou Chefes \\
\hline FG-02 & Coordenadores ou Chefes \\
\hline
\end{tabular}

Fonte: Elaborado pelo autor 
A partir da natureza dos cargos e funções, assim como o coletado nas respostas do questionário e entrevistas, e também na observação direta participante, julga-se que o impacto da implementação, apesar deste não ser o objetivo da pesquisa, de um Programa de Capacitação Gerencial para a organização estudada seria mais efetivo caso a capacitação fosse minimamente segmentada, com base nas atividades e responsabilidades dos gestores.

A proposta é que o programa de Capacitação Gerencial seja segmentado em dois grandes grupos: um grupo que englobe os ocupantes de CD-01, CD-02 e CD-03 com enfoque mais estratégico; além de outro grupo que englobe a CD-04, FG-01 e FG-02 com enfoque mais operacional.

Os cargos de direção 01 e 02 abrangem o alto escalão organizacional, responsáveis por definir as políticas e diretrizes da organização como um todo, possuindo caráter fortemente estratégico. Os cargos de direção de nível 3, ocupados por diretores sistêmicos nos campi da organização estão diretamente atrelados à formulação das políticas dentro das suas unidades acadêmicas. Enquanto as CD-01 e CD-02 possuem abrangência organizacional global, a CD-03, apesar de, na grande parte dos casos, possuir abrangência local (campi de atuação), compõe o núcleo estratégico dos campi, juntamente com seu respectivo diretor geral. Por esta razão, entende-se que um bloco de capacitação com caráter mais estratégico deva abranger os ocupantes dos cargos de direção 01 a 03.

Por outro lado, o cargo de direção de nível 04 apresenta características mais operacionais, se assemelhando, em muitos aspectos, às funções gratificadas. É bem verdade que, nem sempre, tal configuração reflete a realidade de determinado campus, seja pela escassez de cargos existente, pela dimensão e atuação do campus ou mesmo pelo caráter político. Em condições ideais e de igualdade, as funções gratificadas, representadas por chefes ou coordenadores de setores, se assemelham ao CD-04 à medida que desempenham atribuições menos estratégicas e mais operacionais.

Dessa maneira, a referida ação de capacitação gerencial no âmbito de uma IFE segue a seguinte estrutura:

\section{PROPOSTA PARA CAPACITAÇÃO DE GESTORES}

1. Título: Programa de Formação Gerencial - curso

\section{Identificação:}

2.1. Organizador do curso: Diretoria de Gestão de Pessoas da organização.

2.2. Período de realização: a cada nova eleição de Reitor ou Diretor de Campus que acarrete mudança dos seus núcleos gerenciais.

2.3. Características: Grupo I - ocupantes de CD-01, CD-02 e CD-03

Grupo II - ocupantes de CD-04, FG-01 e FG-02

\begin{tabular}{|c|c|c|}
\hline \multirow{6}{*}{ GRUPO I } & MÓDULO I - Conhecimento Organizacional & \multirow{6}{*}{$\begin{array}{l}\text { FOCO } \\
\text { ESTRATÉGICO }\end{array}$} \\
\hline & MÓDULO II - Planejamento Estratégico & \\
\hline & MÓDULO III - Gestão de Pessoas & \\
\hline & MÓDULO IV - Comunicação & \\
\hline & MÓDULO V - Noções de Finanças Públicas & \\
\hline & MÓDULO VI - Noções de Compras Públicas & \\
\hline \multirow{5}{*}{ GRUPO II } & MÓDULO I - Conhecimento Organizacional & \multirow{5}{*}{$\begin{array}{l}\text { FOCO } \\
\text { OPERACIONAL }\end{array}$} \\
\hline & MÓDULO II - Planejamento Estratégico & \\
\hline & MÓDULO III - Gestão de Pessoas & \\
\hline & MÓDULO IV - Comunicação & \\
\hline & MÓDULO V - Noções de Finanças Públicas & \\
\hline
\end{tabular}




\subsection{Modalidade: Presencial}

MÓDULO VI - Noções de Compras Públicas

2.5. Carga horária: 40 horas semanais

2.6. Local: Reitoria ou Campus da organização

\section{Caracterização do Público-Alvo:}

3.1. Número de vagas: sob demanda

3.2. Público-Alvo: Servidores que ocuparem Cargos de Direção dos níveis 01 ao 04 e Funções Gratificadas dos níveis 01 e 02, envolvidos com a gestão de equipes, de processos e de materiais.

\section{Objetivos do curso (gerais e específicos):}

\subsection{Gerais}

- Viabilizar ação de capacitação para desenvolvimento de competências gerenciais básicas aos servidores investidos em cargos e funções de gestão.

\section{Metodologia:}

O Curso de Capacitação Gerencial será dividido em seis módulos, do I ao IV com 08 (oito) horas cada, e do V ao VI com 04 (quatro) horas cada, totalizando 40 (quarenta) horas semanais. Será executado na modalidade presencial, a partir de exposições dialogadas e exercícios práticos, individuais ou em grupos.

Ao final do curso será realizada uma avaliação de percepção dos participantes quanto à estrutura, metodologia e material utilizado na capacitação, bem como a didática dos instrutores.

Após 12 meses será realizada uma avaliação do impacto da capacitação na rotina organizacional dos participantes.

\section{Critérios de avaliação:}

\subsection{Participação nas atividades em sala.}

6.2. Nota igualou superior a $70 \%$.

6.3. Frequência mínima de $80 \%$.

6.4. Avaliação de percepção dos participantes.

6.5. Avaliação do impacto do curso.

\section{Recursos materiais:}

7.1. Recursos físicos: sala de aula, carteiras, data-show, quadro.

7.2. Material didático: apostila.

\section{Conteúdo programático:}

\section{Grupo I - Foco Estratégico}

\begin{tabular}{|l|r|l|}
\hline \multicolumn{1}{|c|}{ Conteúdo } & CH & \multicolumn{1}{|c|}{ Perfil do instrutor } \\
\hline MÓDULO I - Conhecimento Organizacional & & \\
Noções de Administração Pública; & & \\
Criação e contexto dos Institutos Federais; & $08 \mathrm{~h}$ & $\begin{array}{l}\text { Profissional conhecimento e experiência } \\
\text { Noções de Gestão do Conhecimento; } \\
\text { Estrutura e dinâmica organizacional na IFE pesquisada; } \\
\text { Sistemas e rotinas comuns na IFE pesquisada. }\end{array}$ \\
\end{tabular}




\begin{tabular}{|c|c|c|}
\hline $\begin{array}{l}\text { MÓDULO II - Planejamento Estratégico } \\
\text { Modernização da Gestão Pública; } \\
\text { A Prática do Planejamento Estratégico no Setor Público; } \\
\text { Etapas do Planejamento Estratégico; } \\
\text { Ferramentas de Planejamento e Gestão; } \\
\text { Planejamento Estratégico e os resultados organizacionais esperados. }\end{array}$ & $08 \mathrm{~h}$ & \\
\hline $\begin{array}{l}\text { MÓDULO III - Gestão de Pessoas } \\
\text { Legislação de pessoal aplicada ao setor público federal; } \\
\text { Noções de Gestão por Competências; } \\
\text { Liderança. }\end{array}$ & $08 \mathrm{~h}$ & \\
\hline $\begin{array}{l}\text { MÓDULO IV - Comunicação } \\
\text { Comunicação Organizacional Estratégica; } \\
\text { Oratória efetiva. }\end{array}$ & $08 \mathrm{~h}$ & \\
\hline $\begin{array}{l}\text { MÓDULO V - Noções de Finanças Públicas } \\
\text { Receita e despesa pública; } \\
\text { Noções de execução orçamentária e financeira na IFE pesquisada; } \\
\text { Orçamento público como instrumento de planejamento. }\end{array}$ & $04 \mathrm{~h}$ & \\
\hline $\begin{array}{l}\text { MÓDULO VI - Noções de Compras Públicas } \\
\text { Princípios licitatórios; } \\
\text { Modalidades de licitação; } \\
\text { Etapas da licitação } \\
\text { Noções de Contratos Administrativos. }\end{array}$ & $04 \mathrm{~h}$ & \\
\hline Grupo II - Foco Oper & & \\
\hline Conteúdo & $\mathrm{CH}$ & Perfil do instrutor \\
\hline $\begin{array}{l}\text { MÓDULO I - Conhecimento Organizacional } \\
\text { Noções de Administração Pública; } \\
\text { Criação e contexto dos Institutos Federais; } \\
\text { Estrutura e dinâmica organizacional na IFE pesquisada; } \\
\text { Sistemas e rotinas comuns no âmbito da IFE pesquisada. }\end{array}$ & $08 \mathrm{~h}$ & \multirow{5}{*}{$\begin{array}{l}\text { Profissional com } \\
\text { conhecimento e experiência } \\
\text { na temática. }\end{array}$} \\
\hline $\begin{array}{l}\text { MÓDULO II - Planejamento Estratégico } \\
\text { A Prática do Planejamento Estratégico no Setor Público; } \\
\text { Etapas do Planejamento Estratégico; } \\
\text { Ferramentas de Planejamento e Gestão; } \\
\text { Planejamento Estratégico e os resultados organizacionais esperados. }\end{array}$ & $08 \mathrm{~h}$ & \\
\hline $\begin{array}{l}\text { MÓDULO III - Gestão de Pessoas } \\
\text { Legislação de pessoal aplicada a setor público federal; } \\
\text { Motivação e trabalho em equipe; } \\
\text { Resolução de conflitos. }\end{array}$ & $08 \mathrm{~h}$ & \\
\hline $\begin{array}{l}\text { MÓDULO IV - Comunicação } \\
\text { Habilidades comunicativas; } \\
\text { Comunicação assertiva. }\end{array}$ & $08 \mathrm{~h}$ & \\
\hline $\begin{array}{l}\text { MÓDULO V - Noções de Finanças Públicas } \\
\text { Recite e despesa pública; } \\
\text { Noções de execução orçamentária e financeira na IFE pesquisada; } \\
\text { Orçamento público como instrumento de planejamento. }\end{array}$ & $04 \mathrm{~h}$ & \\
\hline
\end{tabular}


MÓDULO VI - Noções de Compras Públicas

Princípios licitatórios;

Modalidades de licitação;

Etapas da licitação

Noções de Contratos Administrativos.
$04 \mathrm{~h}$

\section{Considerações finais}

Este estudo apresentou-se uma proposta para gerar competências básicas em termos de gestão aos servidores de uma IFE nomeados para o exercício de cargos e funções gerenciais.

Foram levantados, inicialmente, os pilares conceituais considerados relevantes, concentrando-se em entender quais as percepções dos servidores da organização acerca da ação gerencial na organização, qual o comportamento dos gestores e ainda, perceber a relevância desse tema no âmbito da organização pesquisada.

A partir de uma amostra representativa, os servidores se posicionaram a respeito de quatorze itens sobre os seus gestores imediatos, cabendo destaque para o item de verificação que apontou que $93,7 \%$ dos servidores entendem que uma organização pública, para atingir níveis satisfatórios de desempenho, deve, necessariamente, trabalhar a capacitação gerencial do seu quadro de gestores.

Ainda sob essa perspectiva, ao entenderem a importância de os gestores estarem minimamente capacitados para o desempenho da atividade gerencial, os servidores foram questionados em que medida o corpo gerencial da organização pesquisada encontra-se capacitado. Foi quando $63,5 \%$ dos servidores discordaram que os gestores se encontram devidamente capacitados para atuarem como gestores.

Dessa maneira, os servidores, ao mesmo tempo em que indicam ser fundamental trabalhar a capacitação gerencial para melhorar o desempenho organizacional, percebem que os gestores não estão minimamente capacitados na organização pesquisada. E é partir da lacuna existente entre o necessário e o real, que os treinamentos são indicados (BRICCH, 1998).

Concluídas as etapas de construção teórico-conceitual e obtida a percepção da importância de se capacitar os gestores para que a organização possa melhorar seu desempenho, a pesquisa voltou-se para as entrevistas com dirigentes do órgão, com objetivo de se apurar os temas considerados essenciais à construção de um programa de capacitação gerencial na organização pesquisada, a partir das experiências, percepções, dificuldades e projeções dos servidores investidos, atualmente ou em tempos passados, nos cargos e funções de gestão.

Para tanto estabeleceu-se, após a realização e transcrição das entrevistas, três categorias de análise representativas da expressão do sujeito da pesquisa, ou seja, baseadas na fala dos entrevistados e codificadas em verbalizações que se associavam, por afinidade conceitual, a temas definidos com base no que fora verbalizado. Essas três categorias de análise levaram sempre em consideração o contexto da organização pesquisada.

De posse dos conhecimentos considerados essenciais a um programa de capacitação gerencial no âmbito da IFE pesquisada, optou-se, a partir das características dos cargos de gestão, de apontamentos do questionário e das entrevistas, bem como da observação direta participante, estruturar o programa de capacitação em dois grupos de público-alvo, ou seja, segmentá-lo conforme os cargos e funções gerenciais existentes na organização, mas sem deixar que o conteúdo se diferencie entre tais grupos. Na verdade, propõe-se uma diferenciação no enfoque do conteúdo a ser ministrado, onde um grupo seria capacitado com objetivos mais estratégicos e o outro com objetivos mais operacionais, sem que ambos percam o caráter gerencial.

Estabelecidos, assim, o arcabouço teórico-conceitual, o levantamento dos dados junto aos servidores a respeito de sua percepção da função gerencial, bem como o levantamento dos dados junto aos gestores e ex-gestores para entendimento daquilo que se considera essencial à prática da gestão na organização pesquisada, este estudo se coloca como uma oportunidade não apenas para a referida organização, mas também às demais instituições 
federais de ensino com características semelhantes, ao propor a construção de um artefato capaz de gerar competências básicas aos seus gestores, através de um programa de capacitação gerencial.

Como limitação deste estudo, tem-se que seu escopo abrangeu duas, de quatro etapas em um processo de treinamento completo: o diagnóstico e a construção. Sendo assim, sugere-se a complementação com as outras etapas, a saber: (1) execução, através da colocação em prática do Programa de Capacitação Gerencial, considerando-se os cenários político e econômico vigentes à época da implantação; e (2) avaliação do programa após sua implantação, para que ajustes, caso necessário, sejam efetuados.

\section{Referências}

ALMEIDA, A. M. P.; MOTTA, F. M. V. O desenvolvimento de Competências Gerenciais como fator de vantagem competitiva: um estudo de caso em uma empresa estatal de telecomunicações. 2012.

BARDIN, L. Análise de Conteúdo. São Paulo: Edições 70, 2011.

BARRETO, Y. Como treinar sua equipe. Rio de Janeiro: Qualitymark, 1995.

BRICCH, Motta. Como escolher o melhor treinamento. Revista Treinamento e Desenvolvimento: Desenvolvendo Talentos. São Paulo, ed. 67, p. 20, jul. 1998.

CAMPOS, D. C. S. Competências gerenciais dos pró-reitores em uma instituição de ensino superior: um estudo de caso na Universidade Federal de Viçosa-MG. Viçosa- MG. 2007 143f. Dissertação (Mestrado) Universidade Federal de Viçosa-MG. Viçosa- MG, 2007.

CRIPE, E. J.; MANSFIELD, R. S. Profissionais Disputados: as 31 competências de quem agrega valor nas empresas. 1. ed. Rio de Janeiro: Campus, 2003.

DUTRA, J. S. Competências: conceitos e instrumentos para a gestão de pessoas na empresa moderna. São Paulo: Atlas; 2004.

DUTRA, J. S. et al. Competências: conceitos, métodos e experiências. São Paulo: Atlas, 2008.

ELIAS, L. et al. Coleção gestão da saúde pública. Maurício Fernandes Pereira; Alexandre Marino Costa; Gilberto de Oliveira Moritz; Denise Aparecida Bunn. (Org.). Contribuições para a gestão do SUS. Florianópolis: Editora Fundação Boiteux, v. 8, 2013.

GIL, A. C. Métodos e técnicas de pesquisa social. 6. ed. São Paulo: Atlas, 2008.

KANAN, L. A.; ZANELLI, J. C. Envolvimento de docentes-gestores com o trabalho no contexto universitário. Psicologia \& Sociedade, v. 23, n. 1, p. 56-65, 2011.

LIBÂNEO, J. C. et al. Educação escolar: políticas, estruturas e organização. São Paulo: Cortez, 2003.

LONGENECKER, C. O.; FINK, L. S. Management training: benefits and lost opportunities (part. I), Industrial and Commercial Training. UK, vol. 37 n. 1, p. 25-30, 2005.

MARRAS, J. P. Administração de Recursos Humanos: do operacional ao estratégico. 14. ed. São Paulo: Futura, 2011.

MILKOVIC, G. T.; BOUDREAU, J. W. Administração de Recursos Humanos. São Paulo: Atlas, 2001.

MINTZBERG, Henry. Managing: desvendando o dia a dia da gestão. Porto Alegre: Bookman, 2010.

MOZZATO, A. R.; GRZYBOVSKI, D. Análise de conteúdo como técnica de análise de dados qualitativos no campo da administração: potencial e desafios. Revista de Administração Contemporânea, Curitiba, v. 15, n. 4, p. 731-747, jul/ago. 2011. 
NASCIMENTO, L. C. N. et al. Saturação teórica em pesquisa qualitativa: relato de experiência na entrevista com escolares. Revista Brasileira de Enfermagem, Brasilia, v. 71, n. 1, p. 228-233, fev. 2018.

OLIVEIRA, D. P. R. Planejamento Estratégico: conceitos, metodologia e práticas. $27^{a}$ ed. São Paulo: Atlas, 2010.

PAIVA, K. C. M.; FERREIRA, L. S. Competências Gerenciais na área de Tecnologia de Informação: um estudo com gestores de empresas localizadas no Triângulo Mineiro. Revista Gestão \&Tecnologia, v. 13, n. 1, p. 205229, 2013.

PASCUCI, L. et al. Managerialism na gestão universitária: implicações do planejamento estratégico segundo a percepção de gestores de uma universidade pública. Revista Gestão Universitária na América Latina GUAL, Florianópolis, p. 37-59, abr. 2016.

PEREIRA, C. S. Memória Organizacional: conceito e práticas em construção. In: ENCONTRO NACIONAL DA ASSOCIAÇÃO NACIONAL DE PÓS-GRADUAÇÃO E PESQUISA EM ADMINISTRAÇÃO, 2013, Rio de Janeiro. Anais... São Paulo, 2013.

PERIN, M. G. et al. O impacto da formação gerencial no desempenho organizacional à luz da abordagem de competências. Brazilian Business Review. Vitória, vol. 6, n. 1, p. 104-120, abr. 2009.

PIRES, L. L. Universidades corporativas: uma nova concepção para o ensino superior? Itinerarius Reflectionis, v. 4, n. 2,11 .

REZENDE, A. M. de. O saber e o poder na universidade: dominação ou serviço? São Paulo: Cortez, 1982.

RUAS, R. et al. Aprendizagem organizacional e competências. Porto Alegre: Bookman, 2005.

RUAS, R. Gestão por competências: uma contribuição à perspectiva estratégica da Gestão de Pessoas. Mimeo, Porto Alegre, 13p, 2003.

SEIFFERT, P. Q. Gestão humana para o século XXI. Rio de Janeiro: Qualitymark, 2005.

SILVA, F. M. V. A transição para a gestão universitária: o significado das relações interpessoais. Revista de Administração FACES Journal. Belo Horizonte, vol. 2, n. 4, p. 72-91, out./ dez. 2012.

STEVENSON, W. J. Estatística Aplicada à Administração. São Paulo: Harbra, 2001. 